\title{
Noninferentialism and testimonial belief fixation
}

\author{
Tim Kenyon, University of Waterloo \\ Uncorrected draft; this paper appears in Episteme,Volume 10, Issue 01, March \\ 2013, pp 73-85
}

I.

Noninferentialism about a class of beliefs is roughly the view that the justification or fixation of those beliefs is not fundamentally a matter of inference from other beliefs (or memories, or observations, on some reckonings). Rather, the relevant belief, its justification, and the doxastic fixation process are often characterized as direct, immediate, unconscious, or belief-independent. Noninferentialist theories of justification have been influential in various sub-fields of contemporary epistemology: for example, as accounts of self-knowledge or of perceptual knowledge (Kripke 1980; Pappas 1982).

The epistemology of testimony, bearing on the fixation and justification of beliefs arising from testimony, has also been thought to benefit from a noninferentialist treatment (Audi 2006, 2003, Pritchard 2004, Weiner 2003). The mere recognition and parsing of testimony is sometimes taken to suffice (defeasibly, no doubt) for justified belief fixation, in some manner that need not involve inference. This approach will appeal both to those general noninferentialists keen to bring testimonial epistemology into the fold of their view, and to those inclined to see testimonial belief as evincing a form of justification that does not reduce to the justification of inference from other beliefs. Suppose we grant, for the most part, the appeal of noninferentialism in such 
domains as self-knowledge and perceptual knowledge. Should we take it to be similarly plausible in the case of believing from testimony?

I think that we should not, for reasons that arise from the particularly complex social and linguistic cognition that appears to underwrite the fixation of beliefs arising from testimony. When we attend to these details, I argue, at least one sort of noninferentialism in testimonial epistemology emerges as an implausible view. It is implausible even on the assumption that the distinction between inferentialism and noninferentialism is a sound one in the domain of testimony, since there is little reason to think that testimonial belief fixation processes show the sort of noninferential purity they would need in order for the view to be correct. But in fact the inferential-noninferential distinction itself is suspect, at least where testimonial belief is concerned. Key supporting notions are ill-defined or polysemous, while both the informal and technical characterizations deployed in the literature to flesh out the distinction turn out to be trivial, unilluminating, or just inaccurate. Hence we should be sceptical of noninferentialism in testimonial epistemology; yet this is no great comfort to anything traveling under the flag of inferentialism. The distinction itself may well rest on an oversimplified view of cognition, and of testimonial doxastic fixation in particular.

II.

The thesis as I have sketched it raises two unavoidable prefatory questions about the phenomena at issue: What is noninferentialism? And what is the relevant notion of belief arising from testimony? 
The main complication in discussing noninferentialism is that it can be a view about two prima facie quite different things. One might hold that beliefs of some interesting class are justified (or count as knowledge) on grounds that do not essentially involve inferential justification. ${ }^{1}$ Or one might hold that beliefs of some interesting class are formed by causal processes that do not include inferences. At any rate, in contemporary philosophy both views travel under the label of noninferentialism, sometimes with little effort to distinguish which view is at issue.

To be sure, there is some reason to doubt the depth of the causal-epistemic distinction in general. This is due not only to the influence of overtly causal theories of knowledge and justification over recent decades, but because some ancillary epistemic concepts seem firmly rooted in the space between the causal and the epistemic, on pretty much any theory of knowledge or justification. The epistemic basing relation is an example of this. Roughly, basing is the epistemic relation that holds between a reason and a belief when the belief is held for that reason. This is widely thought to be a causal notion, or at least a causally-inflected one. ${ }^{2}$ In any case, it has proved much easier to propose cases of causal connections between reasons and beliefs that do not seem sufficient to count as properly epistemic than to give clear examples of justified belief or knowledge in which there is no causal connection to the underlying facts represented by the belief or other epistemic state.

Still, the uncomplicated way for us to deal with this complication is just to distinguish between the causal and the epistemic applications of noninferentialism inasmuch as we can, and then to analyze the two views separately. ${ }^{3}$ This is just what I 
propose to do. The following remarks are directed at causal noninferentialism in the main, leaving for another occasion the question of how problems with the causal view might bear on epistemic noninferentialism. While the causal inferential-noninferential distinction surely has become a matter of interest to epistemologists primarily because of its perceived relevance to issues in justification, it is nevertheless a distinction that epistemologists have come to treat as significant in its own right.

The second prefatory question is: what kind of beliefs are we talking about when we focus on testimonial epistemology? This too implicates the notion of basing, as it turns out. Much of the literature in the epistemology of testimony relies on the notion of testimony-based belief as the phenomenon of interest, a phrase that can be usefully abbreviated 'TBB', thereby saving authors from various inelegant phrasings of the sort I have relied on until now (like 'testimonial belief'). But if the term 'based' is interpreted strictly in accordance with the basing relation, then the phenomenon labeled as TBB will include only those cases satisfying the labeler's standards (whatever they are) for a belief's being held for a reason. And this can lead us back to our first question in very short order - as when Robert Audi writes: "[T] estimony-based belief, as I construe it, and as I think it is normally understood, is never inferential” (2006, p. 27).

Audi takes this view because in testimonial cases he takes genuine basing to hold only between, on one hand, the perception of an act as testimony and a recognition of its semantic content, and, on the other hand, a belief having (more or less) the same content as that testimony. If the reason for which the resulting belief is held includes any other elements, then that belief is not testimony-based in the relevant sense. 
A consequence of this view is that beliefs that are caused by testimony, but whose epistemic bases include other elements, get lumped together in some surprising ways. For example, the case in which a hearer comes to believe that a speaker has a cold because of the congested way she says "I have a cold," even though the hearer doesn't understand her words, is pretty clearly not the core phenomenon that an epistemology of testimony would be concerned to explain. But what about the case in which a speaker asserts a proposition that a hearer parses and comes to believe in light of moreover believing the speaker to be competent and sincere? The former kind of case seems entirely deviant, the latter perfectly straightforward; yet Audi characterizes both cases in terms of "a mere causal relation between a source of knowledge and a belief based on that source" (2006, p. 26).

Why think this? In short, because the latter case involves further judgements that implicate ancillary beliefs about the speaker's competence and sincerity. This information is additional to a mere recognition and parsing of a testimonial act, and so the case is not one of testimony-based belief by Audi's standards:

If... as a ground for believing what you say, I must infer your credibility from background information about you, my belief of your attestation, though acquired through your testimony, may not be said without qualification to be based on it (2006, p. 27). 
On this view, I can gain knowledge through testimony when that knowledge is mediated by beliefs about the speaker; but I can't gain knowledge based on testimony in such a case. And it is testimony-based belief that is the philosophically important phenomenon, on this way of thinking (2006, p. 26).

Audi is not idiosyncratic in this respect. Consider Duncan Pritchard's definition of TBB, in a paper reviewing and summarizing contemporary epistemology of testimony.

In what follows, we will call a 'testimony-based belief' (TBB) any belief which one reasonably and directly forms in response to what one reasonably takes to be testimony and which is essentially caused and sustained by testimony... The belief needs to be directly formed since otherwise other factors will inevitably be brought into play, such as memory (2004, pp. 326-7). ${ }^{4}$

Pritchard too holds that a belief is not really a TBB if it "essentially rests not only on the instance of testimony in question but also on further collateral information gained via observation" (p. 327).

I think it is a needless limitation on the phenomenon of interest to make this definitional stipulation, so I will not focus on TBB, understood in the Audi-Pritchard way. It will be useful to encompass with a single expression the general phenomenon of encountering testimony, understanding it, and coming to believe its content, without defining the expression to rule out that this phenomenon includes the sort of semantically 
rich but informationally impure cases of belief arising from testimony that Audi and Pritchard are at pains to exclude from TBB. I will borrow from Audi the label of a belief from testimony, and call any such belief $B F T .^{5}$ One might argue or discover that BFT is (always, usually, sometimes) TBB. But I see no point in stipulating it in advance of investigation.

On my usage BFT does not include such examples as believing that someone has a sore throat merely because their testimony is delivered hoarsely, nor believing that someone is speaking Spanish merely because their intonations have a Spanish sound to them - that is, not even if what they are saying (unintelligibly, to the hearer) is "I have a sore throat" or "Yo estoy hablando espanol". But it does include non-deviantly coming to believe that a meeting starts at 3 p.m. because Ted said so, when Ted is known to have scheduled the meeting himself - that is, without taking a view on whether that additional knowledge was active in causing the belief. Maybe this last case fails a purity test appropriate to testimonial basing; but I would prefer to begin with an understanding of the phenomenon that leaves room for the prospect that some, perhaps most or all, of our actual BFT counts as impure by that standard.

With these clarifications in hand, I can now state my goals more precisely. I will argue that BFT isn't generally causally noninferential, on the grounds that no characterization of causal noninferentialism is both non-trivial and empirically plausible as applied to it. For one thing, there is too much doxastic information-processing involved in BFT fixation, by and large, for Audi's and Pritchard's purity standards to be generally descriptive of BFT. But some reflection on the typical nature of BFT fixation 
suggests moreover that the inferential-noninferential distinction itself is poorly articulated and oversimplified, at least inasmuch as it is applied to BFT. Hence the implausibility of causal noninferentialism is not tantamount to the plausibility of inferentialism in this domain. For similar reasons, neither does Alvin Goldman's influential notion of a beliefindependent doxastic fixation process, often canvassed as a refinement of noninferentialism, square neatly with the rich and multidimensional details of BFT fixation processes.

III.

"I ask you the time; you tell me it is nine o'clock; and straightaway I believe this on the basis of your saying it." This is Audi, laying out his view of how most testimonyrelated beliefs arise (2006, p. 26). Though he holds that beliefs can arise inferentially as a consequence of encountering, parsing, and evaluating testimony, Audi, as we have seen, interprets the basing relation in such a manner as to make it a definitional truth that TBB is noninferential.

Audi describes TBB as "the kind of belief that arises naturally, noninferentially, and usually unselfconsciously in response to what someone says to us" (2006, p. 26). But it's not all the same to him whether TBB is rare or common in comparison with doxastically contaminated inferential beliefs arising from testimony. In fact he is quite clear in his view that BFT is usually TBB. "Typically," he writes, "we simply understand what is said and believe it...” (2006, p. 27). 
But what does it mean to say that this happens simply? Much of the literature is driven by examples, and especially by examples of the default acceptance of testimony. This is probably due to a perception that the automatic, fast, and implicit acceptance of testimony by default presents the most primitive and least overdetermined or confounded type of testimonial doxastic fixation. If one's view is that BFT fixation generally is noninferential, it will be an inessential complication that some BFT also has an inferential pedigree sufficient to generate the belief. Since the default acceptance of testimony is taken not to demonstrate such inferential processes, default acceptance will strike a causal noninferentialist as a particularly transparent sort of case, well-suited to motivate the noninferentialist view in the first instance.

It is important, then, to note that the default acceptance of testimony is a substantially more complicated process than is typically acknowledged in the discussions and examples of it scattered through the writings on the topic. I doubt that asking someone the time of day is ever as straightforward as is suggested by Audi. In fact there is excellent reason to think that, in context, I don't just ask, you don't just tell me, I don't just believe you, and if this all happens "straightaway," there are at least serious questions of whether this undermines the belief's claim to justified status.

The examples on offer, as well as the positive descriptions of noninferential belief formation and justification, are typically very sparsely detailed. Certainly both Audi's remarks and Pritchard's presuppose a great deal about the cognitive underpinnings of testimony-relevant information processing, without really making clear how these cognitive mechanisms or types could perform as advertised. As we have seen, Audi and 
Pritchard variously depict noninferential belief fixation as direct, unmediated, automatic, and unconscious. While this is fairly standard talk among epistemologists in describing noninferential belief in any domain, the cash value of these characterizations is doubtful.

For example, in Audi's hands, the view that inferences cannot be unconscious is advanced merely on the strength of a rhetorical question: "[I]n what sense can an inference, as opposed to a mental process, be unconscious? This is unclear" (2003, p. 135). To be sure, I am inclined to agree that it is unclear. But it's fair to say that whether some inferences can be conscious is equally unclear. Consider inferences over many premises, conducted over a substantial period of time; or inferences among whose premises are stunningly obvious propositions like 'You can see things better during daylight hours'. Do we consciously entertain these thoughts in drawing inferences; and is consciousness of thoughts the same as consciousness of the inference over the thoughts? Indeed, it's unclear whether inferences even comprise a robust psychological kind, or, if they do, how they are psychologically implemented.

In any case, the conviction that inference cannot be unconscious or automatic is not especially shared by cognitive scientists and psychologists, and has not been for some time. As psychologist John Kihlstrom observes,

Experiments on automaticity are important because they indicate that a great deal of complex cognitive activity can go on outside of conscious awareness, provided that the skills, rules, and strategies required by the task have been automatized. They expand the scope of unconscious 
preattentive processes, which were previously limited to elementary perceptual analyses of the physical features of environmental stimuli. Now it is clear that there are circumstances under which the meanings and implications of events can be unconsciously analyzed as well. Thus, people may reach conclusions about events-for example, their emotional valence - and act on these judgments without being able to articulate the reasoning by which they were reached. This does not mean that cognitive activity is not involved in such judgments and inferences; it only means that the cognitive activity, being automatized, is unconscious in the strict sense of that term and thus unavailable to introspective awareness (Kihlstrom 1987, p. 1447, footnotes elided).

It is possible that Kihlstrom and Audi don't mean quite the same thing by 'inferences' here; for better or worse, this can happen when empirical work meets a (differently) idealized discourse. But Kihlstrom is summarizing the results and interpretations of a great deal of work in cognitive science and psychology. ${ }^{6}$ Even were there a subtle equivocation in play, this in itself would be reason enough to doubt that inference has a transparent interpretation locating it clearly in the realm of the conscious.

Finally, Audi's rhetorical question is surprising by his own lights, given that he distinguishes between two kinds of inferential belief. Episodically inferential belief "arises from a process or episode of inferring, of explicitly drawing a conclusion from something one believes," while structurally inferential belief formation occurs when a 
newly held belief counts as rationally justified in light of other beliefs one holds, and is causally co-determined by those other beliefs, but "is not at the time episodically inferential, because it arises, not from my drawing an inference, but in an automatic way not requiring a process of reasoning $(2003, \mathrm{p} .160)$. The structurally inferential case is explained, "presumably in a causal sense of 'explain"," by the fact that "something happens in me - a belief arises on the basis of one or more other beliefs I hold" (2003, p.160; italics in original). Suppose we granted that reasoning itself is an inherently conscious and non-automatic process, as the quoted passages presuppose. Even so, if structurally inferential belief is, a fortiori, inferential, then it's unclear why Audi thinks that inferential belief formation cannot be unconscious or implicit. That's just what structurally inferential belief seems to be. ${ }^{7}$

Naturally, Audi can use his own distinctions as he sees fit, and I do not claim to have captured the subtleties of his treatment of them. But to both make the episodicstructural distinction and not exploit it looks like acknowledging the fuzzy categories of inference and consciousness, yet perhaps without giving the fuzziness its due significance. In any case, it does seem to count still further against the thought that BFT's causal noninferentiality follows from the claimed unconsciousness or automaticity of BFT fixation. The notions of inference and consciousness are not particularly welldefined, it is true, and their intersection perhaps contains the product of their unclarities; but placing a negation operator in front of 'inferential' does not remedy that.

Nor is there much to recommend claims of the relative unmediatedness or directness of noninferential belief. As Pritchard and Audi have it, an agent's recognizing 
and parsing an assertion leads to a BFT (indeed, a TBB) without her other beliefs, memories, or observations playing an essential causal role. Yet BFT fixation is surely mediated by the influence of lots of other psychological or neurological states and processes. Presumably, the idea that we "just believe" testimony isn't meant to be the claim that we believe testimony without the influence of any mediating psychological processes! But then, if the claim is really to be understood just in terms of directness with respect to inferential processes, we are at risk of turning the claim that noninferential beliefs are direct into the claim that noninferential beliefs are noninferential. Again the illumination offered by the informal characterization is low; the background assumptions signficant; the level of cognitive detail minimal.

With little cognitive or theoretical detail supporting the claimed ubiquity of noninferential BFT formation and justification, there is a particular importance to the examples invoked to illustrate the causal inferential-noninferential distinction for testimony. I argue that these come to grief on just the sort of contextual factors that influence one's dispositions to accept testimony by default, as Audi himself notes.

[O]ne might be habituated to taking intonation and facial features into account. These elements are important constraints on acceptance of much oral testimony, but no specific beliefs need express fully the way such elements constrain the formation of testimony-based beliefs. At least for non-skeptics, a critical stance is possible without reasoning from any of its standards to the acceptability of the testimony, and indeed without inference 
at all. Our critical habits and even our critical standards need not all reside in propositions we believe (2006, p.28).

In other words, Audi quite reasonably recognizes the belief fixation role of what is sometimes called subdoxastic information processing. In distinguishing between strictly inferential operations and the mere "taking into account" of information that constrains testimonial acceptance, Audi alludes to the inferential case as involving specific beliefs and propositions, and to the notion of a mental representation's fully expressing a critical standard. The apparent upshot is that inferential belief fixation depends on cognitive operations over structured representations of a very particular sort: fully-fledged doxastic propositional attitudes.

This is not an understanding unique to any one epistemologist or philosopher of mind, to be sure. Yet the example provided in order to clarify the causal distinction in fact has the opposite effect. It is supposed to show us what (per impossibile, perhaps) inferential BFT would look like, on the view in question. Audi conjectures that

[t]he idea that beliefs based on testimony arise by inference from one or more premises is probably a natural result of concentration on formal testimony. When I hear courtroom testimony, I appraise the witness, place the testimony in the context of the trial and my general knowledge, and accept what is said only if, on the basis of this broad perspective, it seems true (2003, p. 133). 
"Formal testimony," on this usage, seems to be testimony in contexts having formal rules of testimonial evidence. By contrast, Audi holds that "[i]n the case of informal testimony - the most common kind - the beliefs it produces are surely not inferential"' (2003, p. 134). ${ }^{8}$ Rather, we "just believe" testimony when we hear it, provided that it does not trigger a skeptical response from background beliefs that act to "filter" it. Testimony in formal contexts is properly accepted only if the acceptance is supported by one's inferential reasoning, as we are now using the term, about the speaker and the claim (among other things). But this presupposes a fair bit about the cognitive underpinnings of BFT fixation in formal contexts, and the example of formal testimony bears out neither these presuppositions. There are at least two reasons for this failure.

First, there is a double dissociation between the use of conscious critical evaluation standards and formal testimonial contexts. On one hand, intuitively, we may justifiedly believe many things that a witness says in a court of law without any conscious or deliberate appraisal of the sort Audi describes. Indeed, justified default acceptance seems every bit as likely to be the rule as to be the exception in a courtroom, precisely because much of what a witness testifies under oath may be utterly mundane and uncontroversial. ${ }^{9}$ When the courtroom witness states her name and address, for example, the audience hardly goes to palpable inferential lengths in order to "appraise the witness, place the testimony in the context of the trial and [their] general knowledge, and accept what is said only if, on the basis of this broad perspective, it seems true." On the other hand, critical standards of appraisal and evaluation are deployed in innumerable 
"informal" contexts, including in casual conversations between good friends, and among others who generally have a relationship they would characterize as trusting. When a friendly discussion turns to certain topics, or when the claims made on any topic seem worthy of scrutiny, critical evaluative standards come online as a matter of course. If the deployment of these standards is inferential when it occurs in courtroom contexts, then its occurrences in the broad sweep of non-courtroom contexts are every bit as inferential; and if they are not inferential in broader contexts, then it is hard to see why the courtroom case should not also be noninferential. Here too we have a characterization that fails to distinguish inferential from noninferential cases.

IV.

The foregoing point about the courtroom example would follow even if we thought of BFT fixation more generally as either inferential or noninferential in some sharply discrete sense. Yet this thought is doubly fraught. Because:

(A) seemingly canonical inferential BFT formation plausibly incorporates much subdoxastic and implicit information-processing; and (B) seemingly canonical noninferential BFT formation plausibly incorporates much doxastic information-processing - "background" and "foreground." 
These are two manifestations of the tendency for the inferential-noninferential distinction to be a very blurry one. While (A) and (B) do not prove it, they suggest that the inferential-noninferential distinction may simply collapse altogether. What they do show, though, is that conceiving of the divide in terms of causal or historical purity is a nonstarter.

We can see this by reviewing a bit of psychological boilerplate. Cognitive actions like appraising a witness's credibility are demonstrably shot through with the processing of such contextual factors as Audi mentions - the audience is sensitive to the speaker's facial expression and tone of voice, along with many other facts involving dress, race, gender, age, confidence, and social status. Even in a formal setting, this information processing is inextricably linked to one's appraisal of a witness. To choose just one dimension of evaluation: the extent to which an audience perceives that a witness is confident in her own claims is often a significant determinant of how they perceive her credibility (Cutler et al. 1988). Yet the process of assessing a witness's confidence in her own claims, in turn, is an unlikely candidate for explicit, conscious, purely and fully propositional inference. A hearer is unlikely to calculate a speaker's confidence in her claims by consciously considering some explicitly articulated beliefs.

Notice that this point is quite independent of how it seems to hearers that they go about making such assessments, moreover. Well-meaning observers who would deny holding racist views are nevertheless subject to racial stereotype biases when judging the credibility of witnesses (Blair 2001); yet, when this happens, it surely does not seem to them that they reach their credibility judgements on no basis whatever. In such 
circumstances we tend to tell ourselves (and others) a different story about why we trust or distrust the speaker. This sort of story may well include claims to the effect that we reasoned from premises and conclusions in settling on our judgements. Modern cognitive and social psychology has as one of its most heavily repeated themes that implicit heuristic reasoning, activated by feature detection and followed by the confabulation of rationally amenable inferential explanations, is a staple of human mental life.

Nevertheless, observation (A) might seem like grist for the noninferentialist mill: it says that even seemingly inferential belief fixation is partly driven by subdoxastic processes. By dint of being (arguendo) non-propositional, this sort of information processing is not apt to be inferential; hence, even inferential beliefs are also significantly noninferential. Isn't the point of testimonial noninferentialism just supposed to be that inferential justification for BFT, when it occasionally exists, is additional to the more general phenomenon of noninferential justification? So the involvement of subdoxastic information-processing even in inferential cases may seem neither surprising nor problematic for the noninferentialist. But (A) is not as innocuous as one might think, since it underscores the lack of detail available to characterize just what inferential doxastic fixation is supposed to be in the first place.

This is a large and recalcitrant matter that will not be resolved in a few words. It is enough to convey the obscurity of the notion of an inferential pedigree, understood as contrasting sharply with some different form of belief fixation. This implicates the issues that arose in considering Audi's suggestion that inference must be conscious; it turns out 
that psychologists and computational modelers of reasoning apply the notion of inference not just to explicit and articulated logical operations over propositions, but to unconscious processes, to operations like feature detection and classification at the common boundaries of perception and cognition, and even into perceptual processing itself, as with Bayesian inference models of object perception (Kersten et al 2004). It may be up to philosophers, in part, to determine what ought to count as sound, cogent, or rational inference. But epistemologists appealing to a causal notion of inference simpliciter that is dramatically sharper and more limited than the notion of inference actually employed in empirical work surely owe an explication of their own concept. Without that explication, again, we do not create a well-defined phenomenon by negating 'inferential.'

Still, the more obvious problem for noninferentialism is (B). We might think of this in terms of the deeply influential notion of belief-independent belief-formation. Belief-independence looks like a way of spelling out what causal noninferentialism might amount to; (B) is effectively a denial of belief-independence as applied to BFT.

Goldman posits belief-independence as a particular mode of doxastic fixation, characterizing it as a process "none of whose inputs are belief-states" (1992, p. 117). As a refinement on the notion of noninferential belief fixation, this has the virtue of greater clarity. But that such a doxastic fixation process-type is the rule in BFT formation is hard to motivate with psychological evidence, it seems to me. ${ }^{10}$ Indeed, if one thinks about the psychologically complex causal histories of BFTs, and the propensity for those histories to implicate beliefs about persons, about assertions, about intentions, about contexts, 
institutions, rationales, and even clothing, the idea that very many BFTs will have no doxastic contributing causes seems implausible on its face.

Perhaps Goldman is tapping into something like Fred Dretske's (1988) intuition about the distinction between triggering causes and structuring causes in cognition; arguably it is more plausible to think of belief-forming processes that have no beliefs among their immediate triggering causes, even if they output TBBs only because of structuring causal conditions involving beliefs. (Certainly Audi employs the terminology of triggering causes $(2006$, p. 26) in sketching his own causal noninferentialism.) But the triggering/structuring distinction does not track the dependent/independent distinction; a BFT-forming process structured (in part) by beliefs clearly has beliefs among its inputs in the causal sense relevant to whether its output is belief-independent.

Indeed, it is surely through one's "general knowledge" (or in any case one's general beliefs and other attitudes, explicit or implicit) that the links we noted earlier will typically hold between observations of the speaker's facial expression, tone of voice, dress, age, and eye gaze, on one hand, and the acceptance of testimony on the other hand. What explanatory role exists for the notion of, say, my implicit sexism, if not to mediate between my basic feature detection or information-processing regarding sex, and my dispositions to accept or reject testimony offered by people of one (perceived) sex or another? The point applies equally to frequently unarticulated beliefs about race, age, disability, and many other socially freighted properties. Recognizing the effects of such cognitive representations on our social judgements, including our judgements of speaker credibility, is a hallmark of empirically informed epistemic responsibility and social 
awareness. That these influences are insidious is a large part of their perniciousness, when the relevant representations are unwarrantedly negative regarding some oppressed group. Such effects don't arise because one intends them to, nor because one calculates them, but because, as a brute fact, the relevant beliefs, attitudes, memories, and collateral information mediate the cognitive transitions from feature detection to judgement. And while the point is sharpest when we consider the pernicious cases of beliefs and attitudes mediating between feature detection and bigoted judgements, the effect in question is entirely general.

The upshot is that BFTs have complex psychological histories that preclude causal noninferentialism when understood as psychological belief-independence. When I am speaking with someone on my doorstep, my disposition to accept her testimony is without question colored by such details as whether she has just knocked on my door; whether she is a stranger or a neighbor; what I might have experienced or inferred about her reliability as an asserter; what she is carrying; how she is dressed; her hygiene; where she looks while speaking; the company she is keeping, if any; the sort of vehicle, if any, she has arrived in; what day of the week and what time of day or night it is; and whether she is sweating and nervous or seems cool and calm.

Consider also how the content of the speaker's assertions, and its interactions with these contextual details, bears on the plausibility of causal noninferentialism. Does the person on my doorstep claim to be selling something, or distributing religious literature, or canvassing for a charity? Does she express a wish to buy my car? Does she express a wish to buy my children? Imagine someone who claims to be canvassing for a charity 
but is ringing the doorbell at 7 a.m., looking bleary and with no clear sign of literature or a receipt book on his person. Now imagine someone who rings the doorbell at 10:30 p.m., dressed as if for a nightclub and claiming to have discount golf coupons for sale. Surely my settling on judgements about the credibility of such claims psychologically implicates my beliefs and theoretical commitments about that very speaker, persons in general, society, etiquette, times of day, salespersons, companies, charities, hygeine, and clothing, inter alia.

In short, BFT fixation prima facie implicates other beliefs all over the place. At a minimum, then, 'belief-independent' is not a plausible description of BFT when the expression is understood causally, in Goldman's sense of inputs to a formation process.

V.

I am not here concerned to deny that there could be a useful distinction between inferential and noninferential belief fixation in the domains of self-knowledge and perceptual knowledge. But it would be disingenuous to deny that I harbor some skepticism. Indeed, some of my reasoning against the causal inferential-noninferential distinction when it comes to testimony might be recast as objections to that distinction in any domain. The apparent fact that the causal notion of inference is something quite different for at least some epistemologists than it is for psychologists and cognitive scientists (or, worse, that some epistemologists are just getting the causal notion wrong) does not seem idiosyncratic to issues of testimony, after all. 
I am not making that more general case against the inferential-noninferential distinction, though - not because I think that such a case is hopeless, but because the strongest argument for my position regarding BFT is the argument on which noninferentialism fails as an account of BFT even if it succeeds in other domains. ${ }^{11}$ Hence I grant, for current purposes, that causal noninferentialism is well-suited to characterize the epistemically relevant cognitive etiology of coming to believe, for example, that one is in pain, or that one is perceiving a cup. On this assumption, the foregoing remarks show that self-belief and perceptual belief cases are importantly different from cases of coming to believe that a particular speaker in a particular context of assertion, producing an utterance with a particular linguistic content and set of pragmatic overtones, has spoken truly. This strikes me as unsurprising, though.

Paying attention to the typical details of testimonial uptake and belief fixation makes a difference to how we most plausibly characterize the epistemology of testimony. For now, I submit, the reasonable conclusion is that BFT is not plausibly characterized as causally noninferential, but that this should not lead us to characterize it as inferential in some straightforward sense. Causal noninferentialism gives short shrift to the massive overlap of doxastic and subdoxastic cognition in fixing such high-level, complex, socially-inflected beliefs. Yet the assumption of a robust inferential-noninferential distinction for BFT is also dubious in the face of that overlap. ${ }^{12}$ 
${ }^{1}$ This view is defended in various forms by Pappas (1982), Pryor (2005), and Huemer (2007), among others.

${ }^{2}$ That is, basing has been variously characterized in terms of non-deviant causal connections (Moser 1989); in terms of non-deviant causal connection under further metacognitive constraints (Audi 1993); in terms of counterfactual causal (over)determination (Swain 1981); and in various combinations thereof, inter alia.

${ }^{3}$ Some authors use 'epistemic' only as the adjectival form of 'knowledge.' I will use it to apply to knowledge and justification. For the most part my focus is on justification.

${ }^{4}$ Here too note the causal inflection of basing.

${ }^{5}$ As far as I can tell, Audi means more or less the same things by "belief produced by testimony," "beliefs acquired through testimony,", and "belief from testimony" (2006, pp. 26-7). Since he explicitly uses the first expression (at least, without further qualification) to include cases of belief that causally depend only on the manner of utterance, I am not borrowing Audi's definition of BFT - just the convenient phrase itself, with the refinements of meaning I explain below.

${ }^{6}$ For parallel remarks of a similar vintage, see also Gigerenzer and Murray (1987): “The idea that unconscious inferences is a self-contradicting explanation now appears as semantic inertia" (p.103).

${ }^{7}$ This distinction is another example of fairly open traffic between causal and epistemic considerations. Both notions are defined causally, as can be gleaned from the quotes already noted. But the use immediately made of the notions is justificatory. Audi writes 
that an initially noninferential perceptual belief can come to be structurally inferential, if one develops another belief that evidentially supports it. "The addition of this support can justify the belief it supports. If that belief is already justified, it is now doubly so" (2003, p. 161).

${ }^{8}$ In this passage Audi again suggests that BFT is usually noninferential.

${ }^{9}$ C.A.J. Coady (1992, pp. 269-270) makes this point.

${ }^{10}$ Goldman himself does not claim that BFT fixation is belief-independent, to be clear. In fact, he takes it that (what I call) a BFT with propositional content $\mathrm{P}$ is typically the output of belief-forming process that causally implicates another belief - specifically, the belief that the speaker has reported that $\mathrm{P}(1999$, p. 129). My argument here is aimed at the idea that belief-independence, regarded in other domains as a refinement or clarification of noninferentialism, could rescue noninferentialism regarding BFT.

${ }^{11}$ And, of course, because making such a case would be a much larger and far less tractable task.

${ }^{12}$ For very helpful comments, my thanks to David DeVidi, Masashi Kasaki, Rachel McKinnon, John Turri, the members of my 2012 seminar on testimony at the University of Waterloo, and two anonymous referees for this journal. This research was funded in part by Social Sciences and Research Council of Canada Grant 410-2011-1737. 


\section{References}

Audi, R. 2006. 'Testimony, Credulity, and Veracity.' In J. Lackey and E. Sosa (eds.) The Epistemology of Testimony. Oxford: Oxford University Press. 25-49.

Audi, R. 2003. Epistemology: A Contemporary Introduction to the Theory of Knowledge. 2nd ed. Routledge: New York NY.

Audi, R. 1993. 'Belief, Reason, and Inference.' In The Structure of Justification. Cambridge: Cambridge University Press. 233-73.

Blair, I. 2001. 'Implicit Stereotypes and Prejudice.' In Moskowitz, G. (ed), Cognitive social psychology: On the tenure and future of social cognition. Mahwah, NJ: Erlbaum. 359-74.

Coady, C. A. J. 1992. Testimony: A Philosophical Study. Oxford: Oxford University Press.

Cutler, B. L., Penrod, D. S., and Stuve, T. E. 1988. 'Juror Decision Making in Eyewitness Identification Cases.' Law and Human Behavior. 12: 41-56.

Dretske, F. 1988. Explaining Behavior: Reasons in a World of Causes. Cambridge MA: Bradford/MIT Press.

Gigerenzer, G. and Murray, D. 1987. Cognition as Intuitive Statistics. London: Lawrence Erlbaum Associates.

Goldman, A. 1999. Knowledge in a Social World. Oxford: Oxford University Press. Goldman, A. 1992. 'What is Justified Belief?' Liaisons. Cambridge MA: MIT Press. 105-26. Originally published in Pappas, G. (ed), Justification and Knowledge. Dordrecht-Holland: D. Reidel. 1979. 
Huemer, M. 2007. 'Compassionate Phenomenal Conservatism.' Philosophy and Phenomenological Research 74: 30-55.

Kersten, D., Mamassian, P., Yuille, A. 2004. 'Object Perception as Bayesian Inference.' Annual Review of Psychology 55: 271-304.

Kihlstrom, J. 1987. 'The Cognitive Unconscious.' Science 237: 1445-52.

Kripke, S. 1980. Naming and Necessity. Cambridge, MA: Harvard University Press.

Lackey, J. 2008. Learning from Words. Oxford: Oxford University Press.

Moser, P. 1989. Knowledge and Evidence. Cambridge: Cambridge University Press.

Pappas, G. 1982. 'Noninferential Knowledge.' Philosophia 12: 81-98.

Pritchard, D. 2004. 'The Epistemology of Testimony.' Philosophical Issues 14: 326-48.

Pryor, J. 2005. 'There is Immediate Justification.' In Steup, M. and Sosa, E. (eds), Contemporary Debates in Epistemology. Oxford: Blackwell. 181-201.

Swain, M. 1981. Reasons and Knowledge. Ithaca, NY: Cornell University Press.

Weiner, M. 2003. 'Accepting Testimony.' The Philosophical Quarterly 53: 256-64. 